\title{
Como anda a comunicação pública?
}

Pierre Zémor

Após vinte anos de desenvolvimento das competências profissionais, de análise das experiências, de pesquisas incontestes da fortíssima ligação que os franceses possuem com seus serviços públicos, e após grandes esforços de assimilação das tecnologias digitais da informação, em que ponto se encontra a comunicação pública?

Está ela em posição de enfrentar as crises e pronta para responder aos questionamentos atuais, sociais e planetários? Quais são as mutações necessárias dos meios de expressão e de relação?

Primeiramente, compreendamos o que é a comunicação pública. É troca e compartilhamento de informações de utilidade pública ou de compromissos de interesses gerais. Ela contribui para a conservação dos laços sociais. A responsabilidade disso compete às instituições públicas; ou seja, às administrações do Estado, aos serviços das coletividades territoriais, aos estabelecimentos, empresas, organismos encarregados de cumprir uma missão de interesse coletivo. 
Os desafios habitualmente destacados pela comunicação pública são de três ordens: a vizinhança frequentemente ambígua com a política; a tentação de adotar as ideias que reduzem o cidadão a um turista ou cliente da coisa pública; a dificuldade em admitir, perante as mídias, que ela tem como missão específica o serviço ao público, garantindo relações de qualidade, com a finalidade de melhor preencher seu próprio dever de informar.

Além disso, no grande conjunto dos emissores públicos, as comunicações das administrações regionais têm o desafio de tirar da cacofonia que é apresentada aos cidadãos a geometria variável a " $n$ " dimensões das competências, dos embates de financiamentos e a complexidade inaudita dos processos de decisão.

A uma época de abundância digital das fontes de informação e de diluição das responsabilidades editoriais, acrescenta-se o imperativo de garantir a fidelidade dos conteúdos mais do que em outros domínios de comunicação, tendo em vista tratar-se de mensagens pouco afetadas pela chancela da legalidade.

$\mathrm{Na}$ França, muito mais do que em outros entes federativos europeus, onde a comunicação local é prioritária, foi necessário esperar o movimento que nasceu nos anos 1960 ("descolonizar a província" de Michel Rocard ou a aposta sobre o dinamismo regional de Olivier Guichard) e se formalizou nos anos 1980, para liberar a palavra pública e para que as instituições viessem, com isso, procurar a proximidade dos cidadãos.

As instituições públicas aprenderam, apenas no final dos anos 1970 e imitando as práticas que fizeram o sucesso do consumismo, a considerar mais suas clientelas cativas de usuários. As afirmações legais e regulamentadas dos direitos de acesso à informação vieram combater, laboriosamente e às vezes sem sucesso, a cultura do segredo.

Os dirigentes públicos eram mal preparados, nas grandes escolas e nas grandes corporações, para a troca da comunicação. Detentores da verdade outorgavam a informação com parcimônia. Encorajados pelas exigências de descentralização e de transparência nas tomadas de decisões públicas, eles desceram de seus pedestais para se comunicar com os cidadãos: colocar à disposição os dados públicos, informar, explicar, escutar, dialogar.

Pode-se considerar 1989 - ano de nascimento da associação Communication Publique au Conseil d'État (Comunicação Pública no Conselho do Estado) - como um ano de articulação. Dois eventos marcaram, naquele ano, por suas forças simbólicas, as comunicações das instituições públicas e suas percepções na opinião pública: o bicentenário da Revolução Francesa e a queda do Muro de Berlim.

O primeiro pontua na França o longo período de informação transcendente, descendente e condescendente. Ao longo da história, o discurso do interesse geral expresso, no princípio, a favor dos cidadãos - se impôs somente sob os registros do sagrado e do real; dos seguidores de Colbert ou dos jacobinos; do código de Napoleão ou da escola de Jules Ferry; da reconstrução dos anos 1945 ou da Constituição da V República.

O outro símbolo traduz, sobretudo no Leste Europeu, a aspiração de escapar das amarras da informação centralizada e estritamente regulamentada para buscar a salvação nas liberdades do mercado. Cobiçamos uma comunicação ajustada aos tempos do marketing pela visualização publicitária e pela televisão. 
Esses impulsos de se jogar nos braços dessa comunicação são decepcionantes.

Nos encontros europeus, vem a questão de saber se a comunicação institucional pública pode abrir uma via entre os obstáculos colocados por dois paradigmas caricaturais: a promessa do vendedor e a propaganda do político.

A situação de crise financeira e econômica mundial denuncia os erros de um capitalismo selvagem. As "abordagens de marketing" são afastadas. Elas são operantes, apenas, nos ciclos longos de concepção, elaboração, distribuição e serviços concorrenciais. A publicidade, oportuna na concorrência, é inconveniente na carência.

$\mathrm{Na}$ atual conjuntura, são esperadas informações por vezes imediatas e constatadas, aptas a manter ou restabelecer a confiança em um sistema de valores abalado e que deveria ceder mais espaço ao interesse geral.

Não ficou difícil confiar nas empresas que, na hora do desenvolvimento sustentável, souberam colocar adiante sua responsabilidade social, mas, seduzidas pelos jogos financeiros, perderam de vista muitas de suas finalidades generosas?

Após mais de dois anos, a gestão dos grandes grupos foi o teatro de uma batalha interna. Afastamos as comunicações ditas cidadãs em benefício da comunicação financeira, mobilizada em função da satisfação dos acionistas, com ênfase na visualização que certamente contribuiu para a assunção de riscos irrefletidos. Os desvios especulativos mancharam a credibilidade dos propósitos do capitalismo bancário e empreendedor.

A tarefa da comunicação de utilidade pública, política ou institucional é mais do que nunca acompanhar intimamente a ação dos poderes públicos e serviços públicos. Ela pode dar sinais de compreensão e de solidariedade em resposta às demandas irracionais que se apoiam nos temores ou na emoção. Mas é necessário afastar dela os registros de uma comunicação que atrofia o sentido e reduz a capacidade de tratamento de nossa cota de complexidade. Ela deve ter outra criatividade, diferente da que se restringe aos registros da promoção ou da injunção.

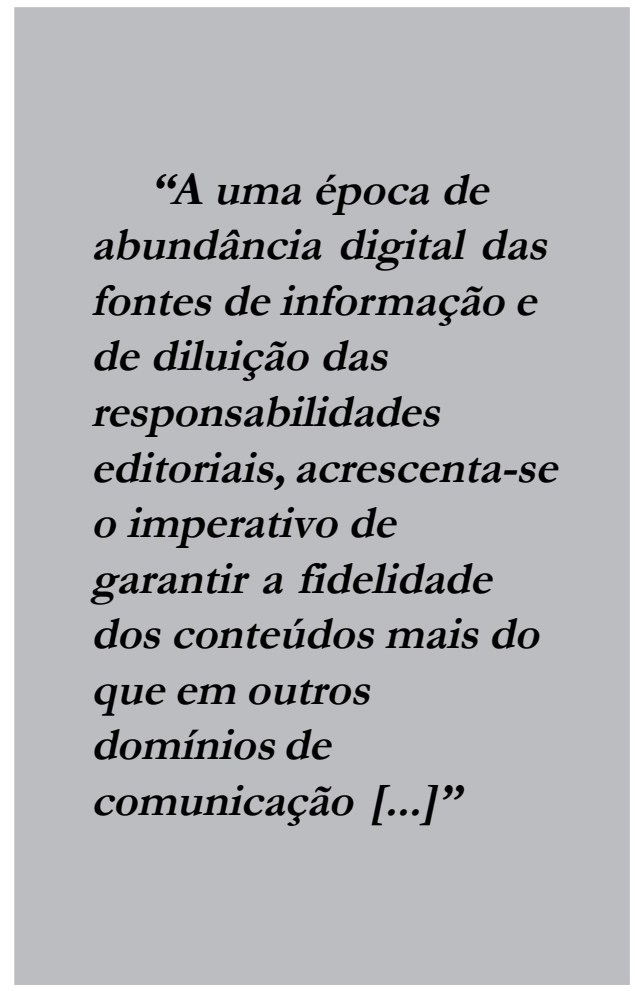

Sair da crise econômica que se instala exige expressar-se sinceramente. Não se poderá mais enganar os que colocam um pouco de esperança nos objetivos do desenvolvimento econômico saneado e adaptado aos modos de crescimento fraco. Saberemos propor a uma sociedade escaldada, mesmo sem princípios ideológicos, mudanças de referências e de garantias de regulações mundiais? 
A consideração dos interesses coletivos impõe uma formação clara e completa, a transparência dos procedimentos de decisões, a explicação e a pedagogia pelo diálogo, a fé no debate público. É pela aptidão para verdadeiras relações que a comunicação é esperada. Pois muitas soluções podem vir do aumento da participação dos cidadãos. As oportunidades do compromisso social crescem com o debate contraditório.

Aqui, a comunicação pública tropeça sobre a pusilanimidade da palavra política, sobretudo ligada à conquista de poder e muito pouco ligada a seu exercício duradouro. As finalidades eleitorais se satisfazem da promessa, do efeito de anúncio e das receitas promocionais dos mercados concorrenciais. Elas se preocupam muito pouco em ultrapassar o imediatismo ou em elevar o nível da informação. O pior ainda é que uma corrente de pensamento, pouco preocupada com o investimento, professa enxergar na política um objeto de consumo.

Quando o marketing endeusa a curva da demanda, a curva da oferta se esvai, apaga-se. A inércia do que foi conquistado nos enclausura na tautologia, como os limites de um questionário fechado de pesquisa.

Faz-se urgente retomar a imaginação política, assim como dar voz aos portadores de novos saberes, aos autores que não abusam das facilidades internautas; em resumo, aos atores mais que a seus dublês mediáticos.

As comunicações públicas, aprendendo a diferenciar suas finalidades nacionais, territoriais, sociais etc., devem inventar formas de reencontrar os interesses para os temas com expressões satisfatórias em falta.

As "grandes causas" sociais e humanitárias, sobretudo as referentes à saúde, segurança e meio ambiente, são bem acolhidas pelas mídias. A ciência, a pesquisa, as artes, a cultura e a história não são objeto, com exceção de raras instituições, de comunicações suscetíveis de ir em direção a um vasto público.

Estes assuntos, essenciais para o futuro e a civilização, esperam mais criatividade para se adaptar a todas as gerações e serem tratados, com as mídias clássicas, digitais ou fora da mídia, de modo mais permanente que eventual.

A comunicação sofre também por cuidar apenas insuficientemente da perenidade de sua relação com a opinião pública. Aliás, faz-se a constatação que a classe política, os eleitos e presidentes executivos, bem como os membros de seus gabinetes, respeitam muito pouco o trabalho de longo prazo das comunicações institucionais praticadas pelos seus próprios serviços.

Os "comunicadores públicos" devem ensinar aos políticos que comunicar não é apenas promover. Para convencer, Obama soube levar as pessoas em consideração. Ele recorreu à internet mais como um instrumento de mobilização dos indivíduos entre si do que para produzir informação de massa. Não é possível tratar uma política pública como "propaganda de TV". Não se vende uma reforma como produto de consumo corriqueiro de catálogo. Reduzir o cidadão a um consumidor é irracional.

Por outro lado, associar os cidadãos a uma melhor qualidade de decisões, supõe "dizer a complexidade das coisas para apelar à lucidez das pessoas", de acordo com uma fórmula, mendeliana, anunciada no final de 1987 por Michel Rocard.

Para colocar essa comunicação na agenda do dia, os atores públicos devem se mostrar aptos a explicar as orientações 
e as medidas objetivadas de acordo com as modalidades que não se reduzem nem às questões jornalísticas, nem às durações curtas propícias às pequenas fórmulas superficiais, tampouco à polarização televisiva sobre as imagens.

A comunicação pública deve, sobretudo, desenvolver o sentido relacional. É a relação com o outro, com o receptor da mensagem, que condiciona o bom encaminhamento do conteúdo. Ela é revestida de tolerância, de compreensão da estranheza, cara a Lévinas. A comunicação é revestida também de gentileza, essa característica considerada como fraqueza, mas que nos coloca no caminho da empatia, do elo social. As atitudes de solidariedade, de fraternidade, lembra Régis Debray, são certamente, com a responsabilidade, as melhores chaves de resolução da complexidade que nos violenta.

As mídias, que devem rever e afirmar sua ética profissional para esta nova época, não podem permanecer indiferentes aos esforços que vão ao encontro de uma divisão mais justa do poder de comunicar, inclusive a fim de garantir ainda mais sua independência fundamental.

Mais do que as instituições, as mídias deverão posicionar-se sobre o custo da comunicação. A reivindicação cresce com acesso gratuito à informação. Ela abre vários debates conexos: disponibilidade total de dados públicos, "gratuidades" da imprensa, downloads na web, o questionamento sobre os direitos dos autores... Vem o questionamento dos valores realmente adicionados por qualquer que seja o emissor: organismo público, jornalista, operador ou intermediário digital, autor, pesquisador ou criador.

Sob a reserva do inventário dos conteúdos emitidos e de crítica das mentiras ou desvios de poder, as mídias não podem mais rejeitar a priori que as instituições e poderes públicos comuniquem de qualquer maneira, para exercer plenamente sua responsabilidade sob os olhos dos cidadãos. A ação pública se conduz comunicação compreendida.

Os excessos do poder mediático contribuem para o desaparecimento da oferta política. Se o Estado, por força dos acontecimentos, aprende a ser modesto, a palavra pública deve ser mais manifestada. Se o propósito de um ministro ou de uma campanha de valorização feita pelo Serviço de Informação do Governo, sobre uma medida ou uma lei, torna-se propaganda, o público, que aprendeu por meio das mídias a ser adulto, sabe decodificar e a mensagem volta como bumerangue ao emissor.

Se buscamos lembrar a separação dos poderes e valorizar novamente o papel do Parlamento, não deveríamos também cuidar para que as mensagens institucionais destinadas às mídias sejam a continuidade de intervenções dos governos diante da representação nacional ou localmente diante de sua assembleia deliberante?

Os jornalistas comentariam o fundo e a forma com recuo, serenidade, renunciando talvez à corrida pela notícia de primeira mão, geralmente desprovida de qualquer valor adicional profissional. A oposição ou os partidos políticos encontrariam mais interesse em intervir ou em exercer, graças às mídias, um direito de resposta verdadeiro. A democracia ganharia certamente. Os jornalistas poderiam orgulhar-se de forma justa em favorecer um verdadeiro debate público.

Além dos imperativos da inovação, os comunicadores públicos praticantes, suas associações, seus conselhos são, eles também, chamados para repensar suas ocupações. 
A sociedade irá conceder muito mais espaço, tanto à participação dos cidadãos na construção do "bem comum" quanto à ética da comunicação.

Para que uma comunicação pública, diversa e atrativa, pluralista, responsável em informar e manter os elos sociais, contribua hoje para a saída da crise e amanhã para vivificar a inteligência coletiva, ela deve procurar, junto às preocupações das pessoas e de suas curiosidades, os registros da autenticidade. 


\section{Resumo - Resumen - Abstract}

\section{Como anda a Comunicação Pública?}

Pierre Zémor

A necessidade de descentralização e de transparência dos procedimentos e decisões governamentais e dos pactos de interesse coletivo levou, na França, ao desenvolvimento da comunicação pública, a partir de 1989. Esse tipo de comunicação deve ultrapassar os objetivos restritos do marketing de vendas das empresas privadas, no qual se inspira para ser a fonte de informação segura para o cidadão. No entanto, esse é um desafio cotidiano, pois a comunicação pública não pode ser confundida com a autopromoção do político. Para isso, é fundamental desenvolver habilidades de comunicação para os servidores públicos de modo que suas orientações para o cidadão sejam claras, acuradas, éticas e justas.

Palavras-chave: comunicação pública, França, comunidades locais, cidadão.

\section{¿Cómo anda la Comunicación Pública? \\ Pierre Zémor}

La necesidad de descentralización y de transparencia de los procedimientos y decisiones gubernamentales y de los pactos de interés colectivo llevó, en Francia, al desarrollo de la comunicación pública desde 1989. Este tipo de comunicación debe superar los objetivos restrictos del marketing de ventas de las empresas privadas, en el que se inspira para ser la fuente de información segura para el ciudadano. Sin embargo, éste es un reto cotidiano, pues la comunicación pública no puede estar confundida con la autopromoción del político. Por eso, es fundamental desarrollar habilidades de comunicación para los funcionarios públicos a fin de que sus orientaciones para el ciudadano sean claras, cuidadas, éticas y justas.

Palabras clave: comunicación pública, Francia, comunidades locales, ciudadano.

\section{What is the current state of art in Public Communication? \\ Pierre Zémor}

The need to decentralize and impinge transparency in governmental procedures and decisions, as well as in pacts of collective interest, has caused, in France, the development of public communication, from 1989 onwards. This kind of communication must go beyond restrictive goals of marketing in private enterprises, from which public communication gets inspiration to become the source of safe information to citizens. However, this is a daily challenge, since public communication cannot be taken by political self promotion. Therefore, it is fundamental to develop communication abilities to public servants so that citizen orientation is clear, precise, ethic and fair.

Keywords: public communication, France, local communities, citizens.

Pierre Zémor

Conselheiro de Estado honorário, presidente da associação Communication Publique. Atuou como presidente da Commission Nationale du Débat Public (Comissão Nacional do Debate Público). É autor, com Patricia Martin, de "Le défi de gouverner, communication comprise" - O desafio de governar, comunicação inclusa - (L'Harmattan - Radio France). 


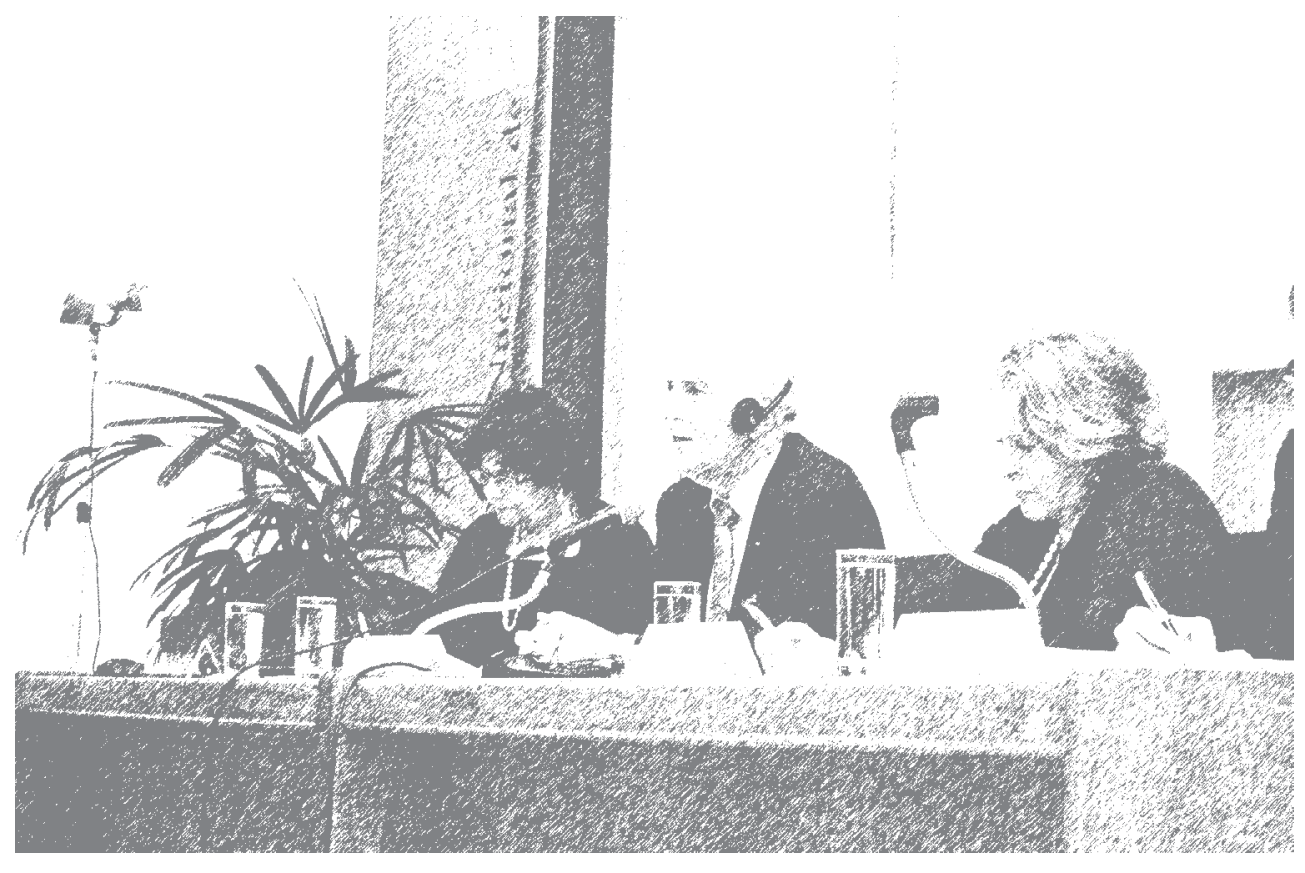

